\title{
Exenatide improves antioxidant capacity and reduces the expression of LDL receptors and PCSK9 in human insulin-secreting 1.1E7 cell line subjected to hyperglycemia and oxidative stress
}

Original Article

Łukasz Bułdak*1, Estera Skudrzyk', Grzegorz Machnik', Aleksandra Bołdys', Rafał Jakub Bułdak², Bogusław Okopień

'Department of Internal Medicine and Clinical Pharmacology, School of Medicine in Katowice, Medical University of Silesia, Katowice, Poland

2Institute of Medical Sciences, University of Opole, Opole, Poland

Received 01 January, 2021, accepted 16 July, 2021

Abstract

Introduction. GLP-1 receptor agonists (e.g., exenatide) are novel drugs used in the treatment of diabetes. These drugs, working with other mechanisms of action, improve glycemic control by increasing secretion of insulin and improving survival of pancreatic islet beta cells. Alterations in the oxidative stress level or the expression of proteins associated with cholesterol uptake might be responsible for those findings. Currently, there are few in vitro studies on the impact of exenatide antioxidant capacity in human islet beta cell lines and none that assess the influence of exenatide on LDL receptors and PCSK9 under hyperglycemia and oxidative stress. Therefore, we evaluated the impact of exenatide on antioxidant capacity, insulin secretion, and proteins involved in cholesterol metabolism.

Materials and Method. An in vitro culture of insulin-secreting cells $1.1 \mathrm{E} 7$ was subjected to hyperglycemia and oxidative stress. Assessment was made of the expression of enzymes associated with oxidative stress (NADPH oxidase, catalase, glutathione peroxidase, superoxide dismutase, iNOS) and cholesterol uptake (LDL receptors, PCSK9). Additionally, insulin and nitrite levels in culture media were quantified.

Results. We showed that exenatide improves expression of catalase and reduces the amount of nitrite in cell cultures in a protein kinase A-dependent manner. Those results were accompanied by a drop in the expression of LDL receptors and PCSK9. Insulin secretion was modestly increased in the culture condition.

Conclusions. Our findings show potential protective mechanisms exerted by exenatide in human insulin-secreting pancreatic beta cell line (1.1E7), which may be exerted through increased antioxidant capacity and reduced accumulation of cholesterol.

Keywords

Exenatide $\cdot$ GLP-1 $\cdot$ pancreatic beta cell $\cdot$ oxidative stress $\cdot$ insulin $\cdot$ PCSK9 $\cdot$ LDL receptor

\section{Introduction}

Type 2 diabetes is a worldwide disease affecting more than 400 million people and increasing in incidence [1]. Causes of the disease are multifactorial. However, insulin resistance and insulin depletion due to pancreatic islet beta cell death or dysfunction seem to be the most prominent causes. Most efforts in current drug development are focused on means to improve insulin sensitivity and beta cell function. As a result, several new drug groups have been introduced to the clinic [e.g., glucagon-like peptide - 1 (GLP-1) receptor agonists]. GLP-1 receptor agonists are drugs that mimic the actions of gut-derived hormones that have been shown to increase secretion of insulin from beta cells, reduce level of glucagon release from alpha cells, and reduce GI tract motility, predominantly gastric emptying [2]. As a result, significant improvements in glycemic control have been achieved, which led to reduced rates of cardiovascular events [3]. Precise mechanisms of protective features of incretin-based therapies on pancreatic islets are not fully known. In preclinical studies exendin-4, which is a GLP-1 receptor agonist, improved the survival of pancreatic islet beta cells in streptozotocintreated mice [4]. One of the potential mechanisms involved in the protection of beta cells is the influence on their antioxidant potential [5]. Previously, it has been shown that GLP-1 receptor agonists reduced oxidative stress in human macrophages [6] and heart muscle [7] and were recovering the oxidative balance in the glial cells [8]. Activation of GLP-1 receptors was shown to possess beneficial effects on oxidative stress and cell survival in beta cells derived from various animals [9]. But we are lacking data from human models. Furthermore, clinical data show that GLP-1 receptor agonist (liraglutide) reduced cholesterol level [6], and it was associated with the change in the expression of LDL receptors and proprotein convertase subtilisin/kexin type 9 (PCSK9) in human liver cell cultures [10]. LDL receptors are responsible for uptake of cholesterol-rich lipoproteins. Their increased expression may lead to intracellular lipid accumulation and worsening

*E-mail: Ibuldak@gmail.com 
of cellular function [11]. Pancreatic beta cells also express LDL receptors and PCSK9, therefore it is postulated that the impact of lipid-lowering drugs (i.e., statins, PCSK9 inhibitors) on the earlier onset of diabetes may result from the induction of LDL-R on the surface, which is responsible for increased cellular cholesterol uptake in animal-derived beta cells, leading to cellular dysfunction [12]. However, the data on human beta cells concerning this subject are scarce. Therefore, we conceived a study to explore the impact of exenatide on the human insulin-synthesizing beta islet cell line (1.1E7) exposed to oxidative stress introduced by hydrogen peroxide. We aimed at the assessment of the oxidative stress marker (nitrite), enzymes involved in such generation (p22 NADPH oxidase, inducible nitric oxide synthase - iNOS) and protection (catalase - Cat, glutathione peroxidase - GPX, superoxide dismutase 1 -SOD1) against oxidative stress. Furthermore, in experiments employing specific inhibitors of intracellular signaling, we wanted to investigate whether the impact of exenatide on human beta pancreatic cells relied on protein kinase $\mathrm{A}$ or phosphoinositide 3-kinase. Finally, we assessed the impact of the selected culture conditions on the expression of LDL receptors, PCSK9 in human beta cells, and the secretion of insulin to the culture media.

\section{Materials and Methods}

\subsection{Cell culture}

Human pancreatic beta cell line (1.1E7) was purchased from European Collection of Authenticated Cell Cultures (ECACC), distributed by Merck Sigma-Aldrich (Poznań, Poland). Cells were thawed according to the supplier's recommendations and cultivated in the RPMI-1640 with $2 \mathrm{mM}$ glutamine supplemented with $10 \% \mathrm{FBS}$ and glucose at final concentration of $400 \mathrm{mg} / \mathrm{dl}$. On the day of the experiment, exenatide, which belongs to the GLP1 receptor agonists (Exendin-4, Cat. No. E7144, Merck Sigma-Aldrich, Poznań, Poland), was reconstituted in water according to the manufacturer's recommendations. Afterwards it was diluted in the culture medium to achieve $10 \mathrm{nM}$ solution of exenatide. In selected culture dishes, 30 minutes prior to the addition of exenatide, PKI (14-22) (a pharmacological inhibitor of protein kinase A - $10 \mu \mathrm{M}$ ), wortmannin (a selective PI3K inhibitor $-100 \mu \mathrm{M}$ ), $\mathrm{H}_{2} \mathrm{O}_{2}$ (oxidative stress inducer $-20 \mu \mathrm{M}$ ), or/and trolox (reactive oxygen species scavenger $-1 \mathrm{nM}$ ) were added to the medium. 1.1E7 cells were incubated at $37^{\circ} \mathrm{C}$ in an atmosphere containing $95 \%$ air and $5 \% \mathrm{CO}_{2}$ in a $\mathrm{CO}_{2}$ incubator (Hera-Cell, Thermo Fisher Scientific, Inc., Grand Island, NY, USA). Experiments were performed under standard conditions for 24 hours. Afterwards samples were collected and stored as described below.

\subsection{Viability}

Viability of cells was estimated using $0.4 \%$ trypan blue method and was performed in a TC-20 automated cell counter (Bio-Rad,
Hercules, CA, USA) according to manufacturer's instructions. Briefly, $10 \mu \mathrm{L}$ of cell suspension was mixed with $10 \mu \mathrm{L}$ of $0.4 \%$ trypan blue, incubated for 3 minutes, loaded onto a sample slide, and assessed in the reader. A total cell concentration in a sample and a percentage of viable cells were obtained. Experiments were performed in duplicate.

\subsection{Nitrite assessment}

Nitrate level was measured colorimetrically by the detection of an azo dye, a product of the Griess reaction, using commercially available total nitric oxide and nitrate/nitrite assay (Cat. No. KGE001, R\&D Systems, USA). Aliquots $(50 \mu \mathrm{L})$ of supernatants were processed according to manufacturer's recommendations. The nitrite level was estimated based on the optical density of each well using a microplate reader set at $540 \mathrm{~nm}$ with a reference wavelength correction at $690 \mathrm{~nm}$ using $\times$ Mark $^{\mathrm{TM}}$ Microplate Absorbance Spectrophotometer (Bio-Rad, Hercules, CA, USA). Experiments were performed in duplicate.

\subsection{ELISA Assay (insulin)}

Cell supernatants were sampled from cell culture directly before cell lysis $\left(1 \times 10^{5}\right.$ cells per well). After removal from the cell culture plate, supernatants were aliquoted in $50 \mu \mathrm{L}$ and frozen at $-80^{\circ} \mathrm{C}$ for ELISA analysis. The concentration of insulin in cell culture supernatant was estimated using Human Insulin ELISA Kit (Cat. No. RAB0327, Sigma-Aldrich, Poznań, Poland), according to the supplier's instructions. The insulin concentration was considered as a surrogate for the level of expression and secretion of this protein to the culture media. Every sample was analyzed in duplicate. The measurements of absorbance at the wavelength of $450 \mathrm{~nm}$ were done using xMark Microplate Absorbance Spectrophotometer (BioRad Laboratories, Inc., Warsaw, Poland). A second measurement at a reference wavelength of $620 \mathrm{~nm}$ was done and this value was subtracted from that of $450 \mathrm{~nm}$. Experiments were performed in duplicate.

\subsection{Western blot}

In the western blot analysis, human-specific antibodies were used as follows: for glutathione peroxidase (GPx): anti-GPX1; for catalase (Cat): anti-Catalase; for cytochrome b-245, alpha polypeptide: Anti-CYBA antibody; and for superoxide dismutase-1 (SOD1): anti-SOD1 (all from Merck Sigma-Aldrich, Poznań, Poland). Antibodies for PCSK9 proprotein convertase: PCSK9 antibody; for inducible nitric oxide synthase (iNOS): iNOS Polyclonal Antibody; and for low-density lipoprotein receptor (LDL-R): LDLR Polyclonal Antibody (all from ThermoFisher Scientific, Warsaw, Poland). For quantitative analysis, a reference glyceraldehyde 3-phosphate dehydrogenase (GAPDH) protein was estimated in every sample using a GAPDH Loading Control Monoclonal Antibody (GA1R) (obtained from Thermo Scientific, Warsaw, Poland). 
Cells were cultured on 12-well culture plates ( $1 \times 10^{5}$ cells per well) (SPL Life Sciences Co., Ltd., Immuniq, Żory, Poland). Prior to cell lysis, plates were placed on ice and cells were washed briefly with $500 \mu \mathrm{L}$ of ice-cold PBS. Protein extraction was done using $150 \mu \mathrm{L}$ of cold RIPA buffer supplemented with $1.5 \mu \mathrm{L}$ of Halt Protease Inhibitor Cocktail (1:100 v/v) per well (both chemicals from Thermo Scientific, Warsaw, Poland). The amount of total protein was measured in each sample by bicinchoninic acid assay (BCA assay) technique and total protein concentration was calculated according to the standard curve based on bovine serum albumin (BSA) solutions of known protein concentration (Thermo Scientific, Warsaw, Poland). Proteins from cell lysates were separated by means of electrophoresis in $10 \%$ polyacrylamide gel in the presence of Color Plus Prestained Protein Marker (New England Biolabs, Lab-Jot, Warsaw, Poland). Total protein $(20 \mu \mathrm{g})$ was loaded into gel slots. After separation, proteins were immediately electroblotted overnight onto PVDF membrane (Merck Millipore, Poznań, Poland) at $100 \mathrm{~mA}$. Nonspecific binding sites were blocked by incubation of the membranes in $3 \%$ bovine serum albumin (BSA) solution in tris-buffered saline (1xTBS) for two hours; membranes were then placed in 3\% BSA/1xTTBS (TBS supplemented with $0.05 \%$ of Tween-20) solution containing one type of antibody at a final dilution of 1:1000, except for antiGAPDH antibody that was diluted to a greater extent (1:2000). Incubations were performed for two hours at ambient temperature with continuous rocking. Then, after two 10-minute washes in TTBS, an anti-rabbit IgG (whole molecule)-peroxidase antibody (Cat. No. A0545, Merck Sigma Aldrich, Poznań, Poland) was added (antibody dilution: 1:10 000 in 3\% BSA/TTBS). Incubation was performed for one hour under continuous rocking. Finally, after three washes (2x TTBS for 5 min. each and 1x TBS for 5 min.), a specific chemiluminescent signal was developed (Pierce ECL Western Blotting Substrate, Thermo Scientific, Warsaw, Poland). After development, membranes were digitized using ChemiDoc-It Imaging System (Analytik Jena, Jena, Germany). Measurements of integrated optical density representing the amount of the protein of interest in a sample were done using ImageJ software [13]. Each figure aggregating data represents 3-5 sets of experiments.

\subsection{Statistical analysis}

The normality of distribution of data was evaluated using Shapiro-Wilk's test. Afterwards data were analyzed using the ANOVA test with post-hoc Tukey test and were reported as means \pm SEM. The $p$ level below 0.05 was considered as statistically significant.

\section{Results}

\subsection{Viability}

In our experimental conditions we have not noted statistically significant changes in the viability of cultured cells in the ex- perimental conditions. This observation stems from the specific culture conditions that were selected to maintain viability and focused on other effects of exenatide on the pancreatic beta cells function.

\section{2 p22 NADPH oxidase expression}

The expression of p22 was not altered in all culture conditions (Fig. 1a).

\subsection{Catalase expression}

Catalase expression (Fig. 1b) was reduced in cells subjected to hydrogen peroxide (34.4\%; $p=0.004$ ). The drop in the catalase level was prevented by the addition of exenatide leading to similar levels of catalase to those observed in cells cultured only under hyperglycemic conditions. The influence of exenatide was depending on PKA activation by exenatide, which was shown in the experiment with PKI 14-22 and which led to reduced expression of catalase (29.4\%, $p=0.047)$. According to experiments with wortmannin, $\mathrm{PI3K}$ did not participate in the action of exenatide. Interestingly, no impact of trolox on the expression of catalase was seen in cells subjected to $\mathrm{H}_{2} \mathrm{O}_{2}$.

\subsection{Glutathione peroxidase expression}

Glutathione expression (Fig. 1c) was modestly affected under culture conditions. Compared to cells treated only under hyperglycemic conditions, the addition of hydrogen peroxide led to an insignificant increase in the expression of GPx. On the other hand, trolox significantly reduced the expression of GPx in beta cells exposed to hydrogen peroxide in hyperglycemic cultures (65\%; $p=0.004)$, which may reflect strong antioxidative properties of trolox that precluded the necessity of catalase synthesis induction.

\subsection{Superoxide dismutase expression}

Superoxide dismutase expression (Fig. 1d) was not changed by any of the experimental conditions.

\section{6 iNOS expression}

Exenatide reduced $(30.9 \% ; p=0.01)$ the expression of iNOS in cells treated in hyperglycemic conditions and with the addition of hydrogen peroxide (Fig. 2a). The influence of exenatide was mediated by PKA resulting in an increased level of iNOS in cells exposed to PKI 14-22 and exenatide (24.5\%; $p=0.048$ ). According to experiments with wortmannin, PI3K seemed to be uninvolved in exenatide signaling. Trolox significantly reduced the expression of iNOS in beta cells cultured with $\mathrm{H}_{2} \mathrm{O}_{2}$ by $33.8 \%(p=0.009)$.

\subsection{Nitrite assessment}

Nitrite level (Fig. 2b) was elevated in cells exposed to hydrogen peroxide (28.8\%; $p=0.001$ ), which may reflect greater activity of the iNOS under oxidative stress. Exenatide in islet cells treated 


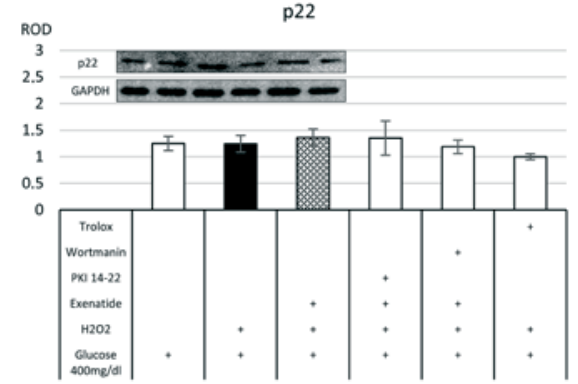

Figure 1c.

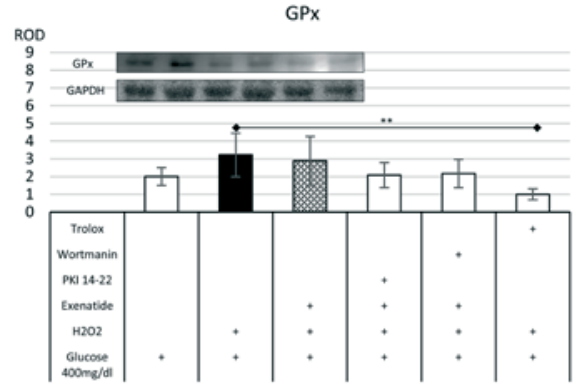

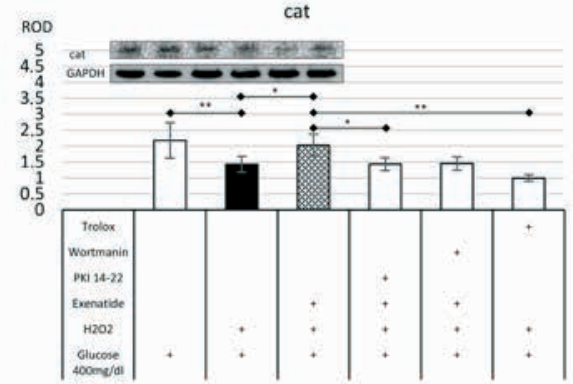

Figure 1d.

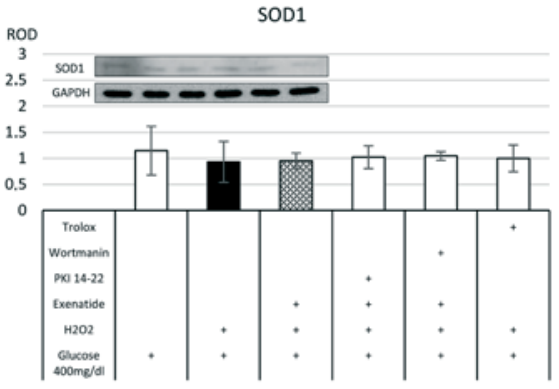

Fig. 1. The impact of exenatide on the level of expression of p22 (a), catalase (b), glutathione peroxidase (c) and superoxide dismutase 1 (d). Data are expressed as means \pm SEM. Asterisks indicate the level of statistical significance: ${ }^{*}-p<0.05,{ }^{* *}-p<0.01$

with $\mathrm{H}_{2} \mathrm{O}_{2}$ reduced the nitrite level by $13.8 \%(\mathrm{p}=0.047)$. Interestingly, both PKA and PI3K inhibition did not change nitrite concentration in exenatide treated cells. In cells exposed to $\mathrm{H}_{2} \mathrm{O}_{2}$, the addition of trolox resulted in a significant drop in nitrite concentration $18.4 \%(p=0.001)$.

\subsection{Supernatant insulin concentration}

Oxidative stress induced by hydrogen peroxide led to a significant reduction in insulin concentration in culture media by $21.5 \%$ ( $p=0.001$ ) (Fig. 3a). Compared to cells exposed to oxidative stress, exenatide was able to increase insulin secretion to culture media (16.6\%; $p<0.05)$. The inhibition of PKA in cells exposed to oxidative stress and exenatide reduced the secretion of insulin to culture media (14.0\%; $p=0.048)$, which showed that insulin secretion after exposure to exenatide is PKA dependent. PI3K did not affect the impact of exenatide. Finally, we noted that trolox prevented the drop in insulin secretion that was seen in cells exposed to hydrogen peroxide.

\subsection{LDL receptor expression}

In the experiments on the influence of $\mathrm{H}_{2} \mathrm{O}_{2}$ on cultured beta cells (Fig. 3b) a significant increase in the expression of LDL receptor was noted (34.7\%; $p=0.013$ ). Compared to cells exposed to hyperglycemia and oxidative stress, exenatide addition to the culture media reduced the level of LDL receptor by $46.6 \%(p=0.001)$, leading to the level observed in cells cultured only in hyperglycemic conditions. The influence of exenatide on beta cells was mediated by PKA, but not PI3K. The reduction of oxidative stress by trolox did not affect LDL receptor expression.

\subsection{PCSK9 expression}

Changes in the expression of PCSK9 (Fig. 3c) in the experimental setting were modest. The only significant change noted was the reduction of PCSK9 level by exenatide in beta cells exposed to oxidative stress and hyperglycemia (by $39.1 \% ; p=0.042$ ). No other statistically significant interactions were noted.

\section{Discussion}

Diabetic patients tend to be at increased risk for oxidative stress [14]. Oxidative stress has been connected with beta cell damage and dysfunction, which is seen in reduced insulin secretion, among other signs [15]. Exenatide, and other drugs that activate the GLP-1 receptor, have been reported to improve beta cell function [16]. The majority of in vitro studies that have been 

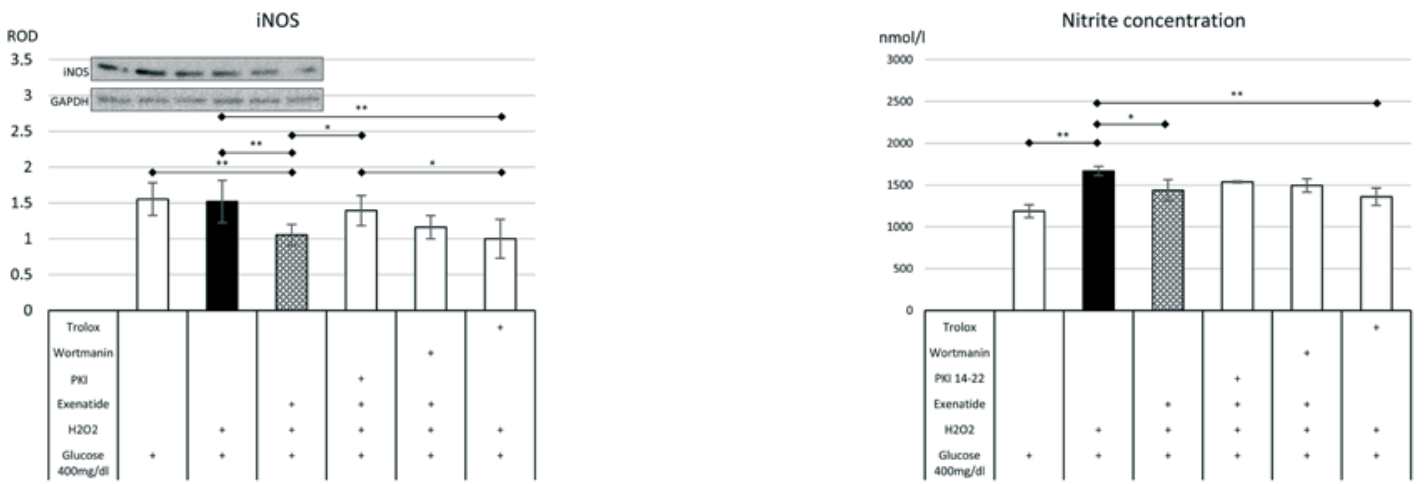

Fig. 2. The impact of exenatide on the level of expression of inducible nitric oxide (a), and the concentration of nitrite in culture media (b). Data are expressed as means \pm SEM. Asterisks indicate the level of statistical significance: ${ }^{*}-p<0.05,{ }^{* *}-p<0.01$

performed so far to explore those observations were performed on animal pancreatic islet beta cell lines. It seems that there is a paucity in the availability of data on human cell cultures. Therefore, we have conducted experiments on the effects of exenatide on the markers of oxidative stress and function (i.e., insulin secretion, LDL receptor expression, PCSK9 expression) of human pancreatic beta cells (1.1E7) subjected to hyperglycemia and hydrogen peroxide.

We found that the exenatide was able to reduce the burden of oxidative stress induced by $\mathrm{H}_{2} \mathrm{O}_{2}$, which was shown by the reduction in the expression of iNOS and nitrite concentration. The inhibitory influence on iNOS level relied on PKA activation exclusively, while nitrite concentration remained unaltered in this regard. This observation may result from a direct impact of PKA activation on protein synthesis rather than the activity of iNOS [17]. Furthermore, we evaluated the expression of several

Figure 3b.

Figure 3a.

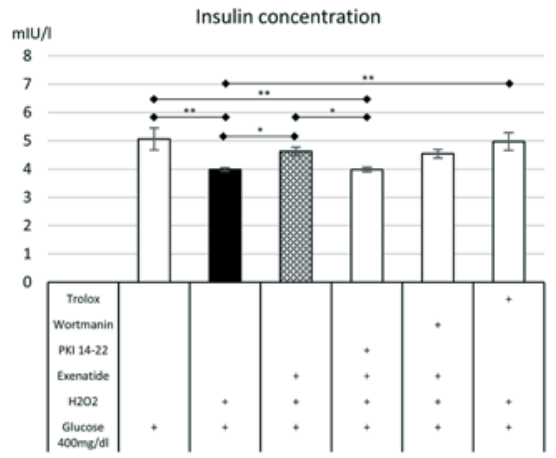

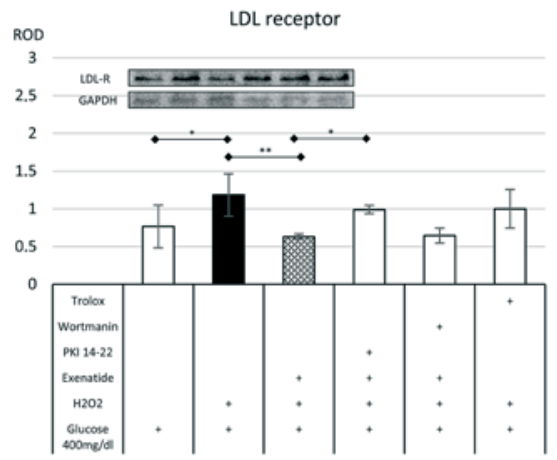

Figure 3c.

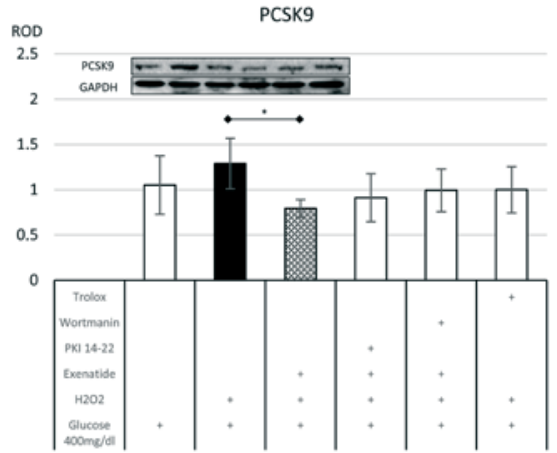


enzymes that are crucial in the generation of reactive oxygen species (p22 NADPH oxidase) and those responsible for reactive oxygen species breakdown (Cat, GPx and SOD). In the employed culture setting (that included hydrogen peroxide) we have not noted any statistically significant impact on p22 - a key player in the generation of ROS. This may be explained by the fact that the external oxidative stress has already been applied and prevented further intrinsic production. On the other hand, exenatide had a significant impact on antioxidant cellular capacity, and restored the expression of catalase in a PKA-dependent manner. The other two antioxidative enzymes remained unaffected by the oxidative stress induced by ROS. Contrary to our observations, in animal studies exenatide seemed to affect all of the above-mentioned antioxidant enzymes except the oxidative stress induced by palmitic acid [18]. This may stem from the different level of oxidative stress introduced to cultures, or from different non-human cell lines. In other experimental settings, cells tend to react more vividly to oxidative stress based on their antioxidant capacity, but ultimately oxidative stress led to cellular dysfunction responsible for shortages in insulin secretion and insulin resistance [19]. It should be kept in mind that the hydrogen peroxide used in our experiments is predominantly dealt by catalase and only to some extent by GPx (till GSH depletion) [20]. This fact may explain the reason for the lack of significant changes in SOD expression in our culture conditions. SOD is responsible for degradation of superoxides and lead to the transient elevation of $\mathrm{H}_{2} \mathrm{O}_{2}$ that is consequently dealt by the other two antioxidant enzymes [21].

Previous studies on human pancreatic islet cells exposed only to hyperglycemia have shown reduced antioxidant enzyme mRNA expression and insulin secretion after $48 \mathrm{~h}$ to $72 \mathrm{~h}$ of culture [22]. Furthermore, the GLP-1 receptor agonist was able to significantly increase insulin secretion, but there were no data reported on the impact of GLP-1 agonist on enzymes associated with oxidative status. This shows potential complex relationships between specific culture conditions, which included glucose concentration and the method of oxidative stress introduction. In our experiments we employed high ( $400 \mathrm{mg} / \mathrm{dL}$ ) glucose concentration in culture media that may be seen in patients with diabetes, especially after meals and a constant exposure to mild oxidative stress using hydrogen peroxide. Hyperglycemia is a natural stimulus of insulin secretion that should result in a significant rise in the insulin level in culture medium. In our study the magnitude of rise in insulin level seemed to be lower than in other studies performed in vitro and in vivo $[9,23]$. The reason for this discrepancy might derive from the specific culture conditions that included exogenous oxidative stress factor. Hydrogen peroxide prominently reduced the secretion of insulin during hyperglycemic conditions. Exenatide was able to partly restore insulin secretion during the oxidative stress. Similar results, but in animal beta cell lines (INS-1) were noted by Kim et al. [24]. On the following step of the experiment we showed that exenatide effects depended on PKA activation. Previously, it was noted that PKC delta is also involved in exenatide action [24]. Several PKC isoforms are activated by hyperglycemia and oxidative stress and are connected with acceleration of diabetic complications [25]. PKC delta is a downstream kinase of PI3K [26]. Therefore, we evaluated the impact of PI3K inhibition on insulin secretion. According to our findings PI3K activation did not participate in the secretion of insulin. The lack of PI3K involvement may result from the potential direct activation of PKC delta by PKA or simply, that the PI3K activation was not connected with a solid reduction of oxidative burden in cultured islet cells.

In the past several years there has been increasing concern regarding the potential diabetogenic effects of lipid lowering drugs [27]. There are studies that connect this observation with increased levels of LDL receptors in pancreatic beta cells, especially during oxidative stress [11]. As a result, an increased uptake of cholesterol and its oxidation may damage beta cells. GLP-1 agonists act protectively on beta cells, but in several studies it was also shown that they may improve lipid profile [28]. Our results showed that exenatide reduced LDL receptor expression in a PKA dependent manner, which may act protectively on beta islet cells. Nevertheless, in cultures that lasted for $24 \mathrm{~h}$ we have not noted any influence on cell survival. On the other hand, insulin secretion was improved in this setting, which showed the additional route of improvement of beta cell function [29]. Surprisingly, the LDL receptor reduction during exenatide exposure was accompanied by a drop in PCSK9 expression. Generally, PCSK9 reduction should lead to decrease in LDL receptor proteolysis. This association is well-described in liver cells, but the function and potency of extrahepatic PCSK9 is not completely understood [30]. It is postulated that PCSK9 function in peripheral tissues stretches beyond the impact on lipid and has more regulatory functions. The participation of PCSK9 in pancreatic islet beta cells warrants further research.

In summary, our results showed that human insulin secreting beta cells participate in oxidative stress management, and the exposure to exenatide reduced oxidative stress markers. Concurrently, exenatide improved insulin secretion during oxidative stress, which was accompanied by reduction in the expression of LDL receptors and PCSK9. Exenatide acted predominantly via PKA activation. We have not observed any significant PI3K participation in the action of exenatide. Potent antioxidant (trolox) was also able to improve insulin secretion and reduce nitrite, as well as iNOS levels.

Limitations of the study should also be kept in mind. The in vitro setting may not fully reflect the complexity of intercellular signaling in living organisms. Cells used in our experiment are in fact hybridomas, which also may affect the observations. On the other hand, the strength of our experiment in including human 
cells is almost unique, as the majority of previous studies relied mainly on animal cell lines.

\section{Acknowledgments}

Authors express their gratitude to Mrs. Jaroslawa Sprada for her expert technical support.

\section{Authors' Contribution}

Ł.B.: research concept and design, carrying out the experiments, analysis and interpretation of data, designing the figures, drafting the article or revising it critically for important intellectual content, writing the manuscript, literature review, final proofreading and approval of the version for publication; E.S.: carrying out the experiments, drafting the article or revising it critically for important intellectual content, literature review, final proofreading and approval of the version for publication; G.M.: carrying out the experiments, drafting the article or revising it critically for important intellectual content, literature review, final proofreading and approval of the version for publication; A.B.: analysis and interpretation of data, designing the figures, drafting the article or revising it critically for important intellectual content, literature review, final proofreading and approval of the version for publication; R.J.B.: analysis and interpretation of data, designing the figures, drafting the article or revising it critically for important intellectual content, literature review, final proofreading and approval of the version for publication;
B.O.: analysis and interpretation of data, drafting the article or revising it critically for important intellectual content, literature review, final proofreading and approval of the version for publication.

\section{ORCID}

Łukasz Bułdak https://orcid.org/0000-0002-2017-5516

Estera Skudrzyk https://orcid.org/0000-0003-2536-3927

Grzegorz Machnik https://orcid.org/0000-0002-9081-0984

Aleksandra Bołdys https://orcid.org/0000-0002-1206-8702

Rafał Jakub Bułdak https://orcid.org/0000-0002-0405-0596

Bogusław Okopień https://orcid.org/0000-0001-7228-2906

\section{Funding}

The study was supported by research grant from Medical University of Silesia.

\section{Conflict of Interest}

The authors have no potential conflicts of interest to declare.

\section{Ethics Approval}

Due to the nature of the research, the consent of the ethics committee was not required.

\section{References}

[1] Diabetes [World Health Organization webpage]. Available at https:// www.who.int/health-topics/diabetes\#tab=tab_1 (Accessed September 2020).

[2] Drucker DJ. Mechanisms of action and therapeutic application of glucagon-like peptide-1. Cell Metab. 2018; 27: 740-756.

[3] Dardano A, Miccoli R, Bianchi C, Daniele G, Del Prato S. Invited review. Series: Implicaions of the recent CVOTs in type 2 diabetes: Which patients for GLP-1RA or SGLT-2 inhibitor? Diabetes Res. Clin. Pract. 2020; 162: 108112.

[4] Juang JH, Kuo $\mathrm{CH}, \mathrm{Wu} \mathrm{CH}$, Juang C. Exendin-4 treatment expands graft $\beta$-cell mass in diabetic mice transplanted with a marginal number of fresh islets. Cell Transplant. 2008; 17: 641-647.

[5] Miki A, Ricordi C, Sakuma Y, Yamamoto T, Misawa R, Mita A, Molano RD, Vaziri ND, Pileggi A, Ichii H. Divergent antioxidant capacity of human islet cell subsets: A potential cause of beta-cell vulnerability in diabetes and islet transplantation. PLoS. One. 2018; 13: e0196570.

[6] Bułdak Ł, Machnik G, Bułdak RJ, Łabuzek K, Bołdys A, Belowski D, Basiak M, Okopień B: Exenatide (a GLP-1 agonist) expresses anti-inflammatory properties in cultured human monocytes/macrophages in a protein kinase A and B/Akt manner. Pharmacol. Rep. 2016; 68: 329-337.
[7] Zhang P, Li T, Wu X, Nice EC, Huang C, Zhang Y: Oxidative stress and diabetes: Antioxidative strategies. Front Med. 2020; 14: 583-600.

[8] Bułdak RJ, Bułdak Ł, Kukla M, Gabriel A, Zwirska-Korczala K. Significance of selected antioxidant enzymes in cancer cell progression. Pol. J. Pathol. 2014; 65: 167-175.

[9] Kondo M, Tanabe K, Amo-Shiinoki K, Hatanaka M, Morii T, Takahashi H, Seino S, Yamada Y, Tanizawa Y. Activation of GLP-1 receptor signalling alleviates cellular stresses and improves beta cell function in a mouse model of Wolfram syndrome. Diabetologia. 2018; 61: 2189-2201.

[10] Yang SH, Xu RX, Cui CJ, Wang Y, Du Y, Chen ZG, Yao YH, Ma CY, Zhu CG, Guo YL, et al. Liraglutide downregulates hepatic LDL receptor and PCSK9 expression in HepG2 cells and db/db mice through a HNF-1a dependent mechanism. Cardiovasc. Diabetol. 2018; 17: 48.

[11] Perego C, Da Dalt L, Pirillo A, Galli A, Catapano AL, Norata GD. Cholesterol metabolism, pancreatic $\beta$-cell function and diabetes. Biochim. Biophys. Acta Mol. Basis Dis. 2019; 1865: 2149-2156.

[12] Ramin-Mangata S, Blanchard V, Lambert G. Key aspects of PCSK9 inhibition beyond LDL lowering. Curr. Opin. Lipidol. 2018; 29: 453-458.

[13] Abramoff MD, Magalhaes PJ, Ram SJ. Image processing with ImageJ. Biophotonics Inter. 2004; 11: 36-42. 
[14] Zhang $H$, Forman HJ. Acrolein induces heme oxygenase-1 through PKC-delta and PI3K in human bronchial epithelial cells. Am. J. Respir. Cell. Mol. Biol. 2008; 38: 483-490.

[15] Kajimoto Y, Kaneto H. Role of oxidative stress in pancreatic $\beta$-cell dysfunction. Ann. N.Y. Acad. Sci. 2004; 1011: 168-176.

[16] Yap MK, Misuan N.: Exendin-4 from Heloderma suspectum venom: From discovery to its latest application as type II diabetes combatant. Basic Clin. Pharmacol. Toxicol. 2019; 124: 513-527.

[17] Bułdak Ł, Machnik G, Skudrzyk E, Bołdys A, Okopień B. The impact of exenatide (a GLP-1 agonist) on markers of inflammation and oxidative stress in normal human astrocytes subjected to various glycemic conditions. Exp. Ther. Med. 2019; 17: 2861-2869.

[18] Alnahdi A, John A, Raza H. N-acetyl cysteine attenuates oxidative stress and glutathione-dependent redox imbalance caused by high glucose/high palmitic acid treatment in pancreatic Rin-5F cells. PLoS. One. 2019; 14: e0226696.

[19] Newsholme P, Keane KN, Carlessi R, Cruzat V. Oxidative stress pathways in pancreatic $\beta$-cells and insulin-sensitive cells and tissues: Importance to cell metabolism, function, and dysfunction. Am. J. Physiol. Cell Physiol. 2019; 317: C420-C433.

[20] Rocha S, Gomes D, Lima M, Bronze-da-Rocha E, Santos-Silva A. Peroxiredoxin 2, glutathione peroxidase, and catalase in the cytosol and membrane of erythrocytes under $\mathrm{H}_{2} \mathrm{O}_{2}$-induced oxidative stress. Free Radic. Res. 2015; 49: 990-1003.

[21] Bułdak Ł, Łabuzek K, Bułdak RJ, Machnik G, Bołdys A, Okopień B. Exenatide (a GLP-1 agonist) improves the antioxidative potential of in vitro cultured human monocytes/macrophages. Naunyn Schmiedebergs Arch. Pharmacol. 2015; 388: 905-919.
[22] Vasu S, McClenaghan NH, McCluskey JT, Flatt PR. Cellular responses of novel human pancreatic $\beta$-cell line, 1.1B4 to hyperglycemia. Islets. 2013; 5: 170-177.

[23] Kim MH, Kim EH, Jung HS, Yang D, Park EY, Jun HS. EX4 stabilizes and activates Nrf2 via $\mathrm{PKC} \delta$, contributing to the prevention of oxidative stress-induced pancreatic beta cell damage. Toxicol. Appl. Pharmacol. 2017; 315: 60-69.

[24] Kim JY, Lim DM, Moon Cl, Jo KJ, Lee SK, Baik HW, Lee KH, Lee KW, Park KY, Kim BJ. Exendin-4 protects oxidative stress-induced $\beta$-cell apoptosis through reduced JNK and GSK3 $\beta$ activity. J. Korean Med. Sci. 2010; 25: 1626-1632.

[25] Geraldes P, King GL. Activation of protein kinase $C$ isoforms and its impact on diabetic complications. Circ. Res. 2010; 106: 1319-1331.

[26] Zhang L, Tian J, Diao S, Zhang G, Xiao M, Chang D. GLP-1 receptor agonist liraglutide protects cardiomyocytes from IL-1 $\beta$-induced metabolic disturbance and mitochondrial dysfunction. Chem. Biol. Interact. 2020; 332: 109252.

[27] Ooba N, Setoguchi S, Sato T, Kubota K. Lipid-lowering drugs and risk of new-onset diabetes: A cohort study using Japanese healthcare data linked to clinical data for health screening. BMJ Open. 2017; 7: e015935.

[28] Aoki K, Kamiyama H, Takihata M, Taguri M, Shibata E, Shinoda K, Yoshii T, Nakajima S, Terauchi Y. Effect of liraglutide on lipids in patients with type 2 diabetes: A pilot study. Endocr. J. 2020; 67: 957-962.

[29] Roehrich ME, Mooser V, Lenain V, Herz J, Nimpf J, Azhar S, Bideau M, Capponi A, Nicod P, Haefliger JA, Waeber G. Insulin-secreting $\beta$-cell dysfunction induced by human lipoproteins. J. Biol. Chem. 2003; 278: 18368-18375.

[30] Kockx M, Kritharides L. Pancreatic PCSK9 and its involvement in diabetes. J. Thorac. Dis. 2019; 11: S2018-S2022. 